\title{
Innovation and technology transfer: a framework for clustering intermediation roles
}

\author{
João Soares \\ Department of Production and Systems \\ University of Minho \\ Guimarães, Portugal \\ https://orcid.org/0000-0002-0263-3915
}

\author{
Fernando Romero \\ Department of Production and Systems \\ ALGORITMI Research Centre \\ University of Minho \\ Guimarães, Portugal \\ https://orcid.org/0000-0002-7540-8540
}

\author{
Manuel Lopes Nunes \\ Department of Production and Systems \\ ALGORITMI Research Centre \\ University of Minho \\ Guimarães, Portugal \\ https://orcid.org/0000-0003-1313-2523
}

\begin{abstract}
Intermediation has become a key role in the complex realm of technology transfer projects. In innovation and technology transfer literature the number of mentions on intermediaries and their involvement in the process have expanded, which has triggered a surge in specific literature on the intermediation roles. Several authors have not only proposed new intermediation roles but also complemented and clarified previous ones. In this research, a review of the literature is made, focused on the role and involvement of intermediaries in innovation and technology transfer, covering more than thirty years and referring to four major databases. Following the analysis and discussion of the findings, the results are synthetized in a conceptual framework proposal, clustering thirteen key intermediation roles. Each of these role clusters describes a set of responsibilities, functions and main intermediation activities. Findings show that when it comes to intermediation roles, literature is yet too fragmented and scattered, with little to no connections between the proposed roles. The main contribution of this paper is to contribute to and to provide a comprehensive overview of otherwise scattered and disperse knowledge about the intermediation role.
\end{abstract}

Keywords- Intermediation roles, Technology Transfer, Innovation Intermediaries, Innovation Systems, Literature Review.

\section{INTRODUCTION}

Innovation and technology transfer activities happen in the context of highly dynamic innovation ecosystems and are dependent on several variables to function properly, such as the features of the innovation network, R\&D funding, technology intermediation, market knowledge and public support [1], [2]. With the increasing emergence of open innovation systems, intermediary's basic role of diminishing market and systems failures evolved into a more complex intermediation system composed by a variety of intermediary agents [3]. Intermediation became a key part of the innovation and technology transfer process, with intermediaries developing new roles and capabilities as more and more technology recipients and technology sources look for support to reduce market inefficiencies and systemic gaps [4]. Despite this, the complexity of intermediation process as well as the variability of intermediary agents are still insufficiently characterized in literature, reflecting an oversimplified misconception of what really is the intermediation role.
Nonetheless, in the innovation systems' literature, especially on subjects like innovation management and technology transfer, intermediaries have gained more and more relevance, in both a qualitative and an exploratory way, with studies looking to label, describe and understand intermediaries and their roles in the process [5]-[7]. This paper follows Howells' [8] perspective as a starting point, as he defines an intermediary as "an organization or body that acts as an agent or broker in any aspect of the innovation process between two or more parties". From an alternative perspective, Dalziel [9] offered a different description, affirming "innovation intermediaries as organizations or groups within organizations that work to enable innovation". This alternative definition highlights the organizational perspective of innovation intermediaries.

In the last decades, with the growth and acceptance of the Open Innovation idea [10], innovation intermediaries have started to be more recognized entities and have acquired broader roles. Following the Open Innovation model [11], organisational actors started to take advantage of strategic intermediaries as experts that can help in obtaining and processing information and facilitating funding access, which can support transactions between stakeholder parties [12]. Studies have been shedding light on understanding the complexity of intermediaries organisations and how their roles are essential to keep up with the system's needs through sophisticated innovation strategies and management principles [8], [13]. With the ever growing emergence of new kinds of intermediary agents, there are yet intermediaries entities and roles to be explored and understood in the research literature [14]-[17].

With much to be explored and analysed on the roles intermediaries can play in innovation systems, in this research paper a review of the literature is made, focused on the role and involvement of intermediaries have in innovation and technology transfer, covering a thirty year period span and resorting to four major scientific databases. This review intended to further explore and update literature understanding on the complexity of intermediation roles, based on the analysis and synthesis of this literature review findings. 


\section{TECHNOLOGY TRANSFER AND INTERMEDIARIES}

In the innovation systems point of view, the technology transfer process has changed over the years, evolving from a linear into a non-linear and systemic process, much more complex and with a wider range of actors [8]. Technology transfer requires much more than only technology providers and business recipients, depending also on intermediary organisations to fill systemic gaps in the process, compensating for weaknesses in the innovation system [18]-[20]. Many of these weaknesses and market failures have been tackled by public mechanisms such as activity incentives, however the market by itself has not enough incentives to tackle every gap [21], [22]. More complex failures are inherent to the system itself, resulting commonly from interaction problems between the agents [23].

The Open Innovation model contributed to knowledge about technology transfer in the last 20 years. Open innovation brought a new perspective to innovation systems [8]. With more emerging organisation playing broader roles to fulfil gaps in the system, more innovation management scholars [8], [11], [24], [25] also started exploring the variety of intermediary organisation types, their roles and their importance to the national innovation systems [8], [15], [26]-[29]. This model describes an innovation system in which industry relies on Research and Development resources from other system agents [11], [12], and also on the collaborative ecosystem strategies open innovation approaches can foster, such as cooperation and strategic alliances among several types of agents from the innovation ecosystem. Following this open innovation perspective, the emergence of more actors in the ecosystem poses as an opportunity for both providers and recipients [8], [30], and provides alternative mechanisms to tackle systemic failures.

With literature evidence on the rapid growth of more and new types of intermediary organisations in the system, most of the literature defines and categorizes innovation intermediaries with terms such as: "intermediaries", "brokers", "mediators", "consultants", "third-parties" or "bridge organisations" [31]. Battistella [17] argues that the intermediary figure, as a concept actor in the innovation system, may, or may not be, directly involved on the technology transfer process. These changing patterns earned innovation intermediaries a specific body of literature on its own [8], [17], [32]-[34], in which several authors have studied the role of these emerging organisations and their role in the innovation/technology transfer process [32].

\section{MethodOLOGY}

The literature review was developed following the six steps specified by [35]: (1) defining the research questions; (2) defining the criteria for sample collection required for the study (3) obtaining a sample of the potentially relevant literature; (4) selecting the relevant literature; (5) synthesizing the literature; and (6) reporting the results.

The review presented in this paper was conducted following a key research question: "Which are the set of intermediation roles intermediary agents fulfil alongside technology transfer projects?".
The search was made relying on four databases (Web of

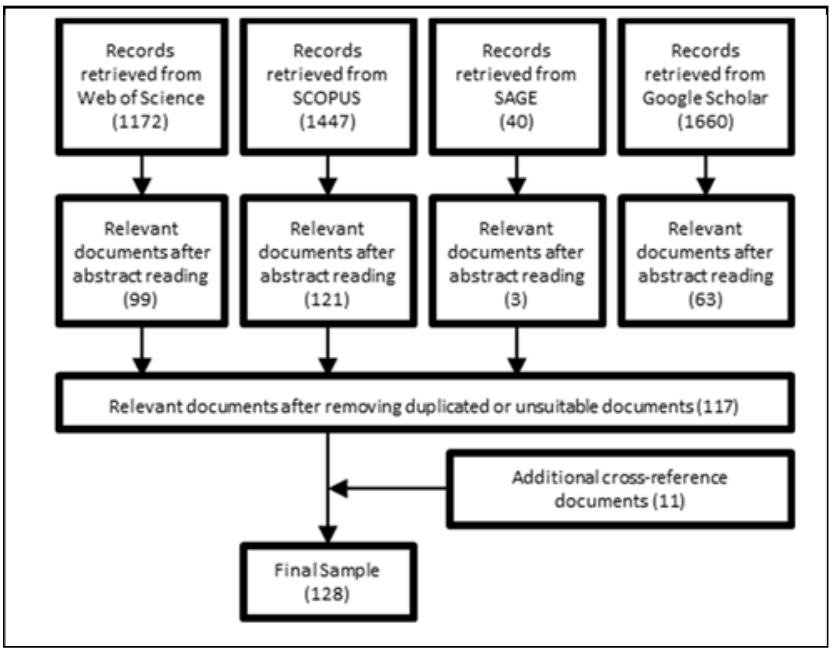

Fig. 1. Research methodology

Science, Scopus, SAGE and Google Scholar), was limited to articles and reviews and covers thirty years from 1990 to 2020, retrieving an initial total of 4319 documents, further filtered through specific exclusion criteria to a final sample of 128 documents used in this literature review. Figure 1 summarizes the screening process followed.

\section{RESULTS AND DISCUSSION}

This section reviews and discusses the obtained literature findings for the research question previously defined. Based on the final sample of 128 documents, the involvement of intermediaries in technology transfer is analysed, tracking the roles, activities and intermediation focus proposed, described and complemented by several authors in the innovation intermediary's literature.

The literature on technology transfer, innovation management and systems of innovation has identified various roles for technology intermediaries [8], [36], but it wasn't always like that. Most authors before [8], especially in the technology transfer related literature, usually summarized and generalized the functions of intermediary agents into two key roles: "brokering" as a main function during the innovation and/or technology transfer process and "networking", the typical role of an intermediary in the innovation system, where he provides and maintain the right connections and network conditions in a defined sector or industry and within its main stakeholders [15]. Authors in [37], [38] added two other major activity focus required for intermediaries, the "communication" and the "scanning and gathering information" activities which were a milestone in understanding the larger potential of intermediaries' role in sustaining innovation systems and technology transfer processes [17].

Nonetheless, authors agree that the intermediary's role in technology transfer is far more complex than only providing the mediation of networks and brokering activities, the most highlighted roles in technology transfer models and literature. For instance, [27] shows that private consultants had a particular 
role as a kind of innovation bridge by playing a list of key bridging activities, very much similar to what could be seen as intermediation activities, such as (1) articulation of needs and selection of options, (2) identification of needs and selection training, (3) creation of business cases, (4) communications and development, (5) education and link to external info and (6) project management activities, such as managing external resources and organisational development. But even with the development of the innovation intermediary's literature, most innovation intermediary roles and activities in innovation and technology transfer literature were still relatively vague and stated in general terms, describing an intermediary focus, more than an actual role. Examples of this are building linkages with external knowledge providers, providing specific knowledge of technology and industries, articulating, diagnosing and evaluating technologies to be transferred, establishing relational binding for technology transfer agents to facilitate transactions and providing guidance and implementing innovation policy [8], [18], [20].

When it comes to intermediation roles, activities, responsibilities or focus, most of the literature is largely fragmented and scattered through hundreds of publications under different terms and designations, different descriptions and little to no connections between the proposed roles. Some authors started to create and propose modular frameworks to categorise, structure and connect intermediation roles through different conceptual logics. Example of that is [39], who saw intermediaries more as innovation "coordinators", responsible for coordination activities, and proposed a framework with three main coordination categories: "network", "cooperation" and "political". Other authors also have been distinguishing the roles and types of intermediaries by their roles in cluster domains such as "problem solving", "technology transfer" and "coordination of networks in innovation systems" [13], [40], [41].

Howells [8] contributed highly to the innovation intermediaries' literature by presenting a study with a greater indepth on the kind of activities innovation intermediaries play and why they are becoming key agents in innovation systems. Further corroborated by [31], [8] showed that innovation and technology intermediaries play a wide spectrum of roles, ranging from diffusion and technology transfer to innovation management, and even offering knowledge intensive services in several steps of the project, from the idea conception, problem solving, matchmaking, intellectual property including concrete technology brokering and commercialization.

In what concerns innovation intermediaries' roles, the contribution of [8] is still widely accepted, where ten key functions are , namely: (1) foresight and diagnostics; (2) scanning and information processing; (3) knowledge processing and combination/recombination; (4) gate keeping and brokering; (5) testing and validation; (6) accreditation; (7) validation and regulation; (8) protecting the results; (9) commercialisation; and (10) evaluation of outcomes. Several authors have followed [8] framework of the activities intermediaries play on both innovation and technology transfer, and have complemented and added up new roles and activities to the innovation intermediaries [42], such as: "forecasting and road mapping" [8], [15], [43], "information gathering and dissemination" [8], [27], [44]; "fostering networking and partnerships" [27], [31], [43]; "prototyping and piloting" [45]; "technical consulting" [8], [46]; "resource mobilisation" [8], [27], [47], [48]; "commercialisation" [8], [27], [48]; "branding and legitimation" [43], "investment appraisal analysis" [46] and "definition of innovation needs" [15], [46].

\section{A. Intermediation roles}

Based on the literature it was possible to identify not only the existence of different terms to refer the same role and activities, but also several activities that can be under the umbrella of the same categorisation. But even through the combination and merge of several similar roles, the spectrum of intermediary's responsibilities and activities would still be too wide and fragmented to be analysed, sometimes even varying or overlapping as different intermediary types could have similar intermediation focus under different roles. In order to respond to the research goals in a detailed, yet compiled, analysis, a framework was developed and proposed, combining and systemising the discussion, following a synthetized approach to the review findings, and adopting as a categorization criteria the key roles clusters that the intermediary, as a concept, can have alongside the technology transfer process.

The developed set of role clusters used as its baseline the framework proposed by [8], but also took into consideration the wide, and more recent, set of contributions and add-ons roles and designations found, proposed and highlighted by several authors reviewed in this theoretical research. The result is the proposal of a framework synthetizing the review findings in 13 key role clusters (Table I), each describing a particular focus that an intermediary agent, as a concept, can have and what specific roles, responsibilities and activities the literature review found to be part of or related.

Major implications highlighted by the authors with this literature review focus mainly on understanding the complexity of intermediation as a concept key role in innovation and technology transfer. The proposed framework aims to go beyond updating and structured clustering of the data found dispersed in the literature, looking also to emphasize the importance of the intermediary as a strategic agent in innovation systems, in order to orient future theoretical developments in this domain. The literature review findings have also practical implications, by shedding light on the larger range and potential of the intermediaries' role in response to systematic gaps, reflecting the need to adjust innovation policies, strategies and practices that can make the most of this under-exploited agent.

The results showed an extension of the traditional intermediary roles in innovation systems and technology transfer literature. However, the true value of the proposed framework is still limited by the need to further develop a comprehension of which of these roles are in fact played by each type of intermediary. Thus, the literature analysis points to future research directions by recognizing a lack of synthesized comprehension about the range of intermediation entities operating in the system, namely on how they differ from each other and which of the intermediation roles can be matched to each of them. 
TABLE I - Intermediation Role Clusters

\begin{tabular}{|c|c|c|c|}
\hline \# & Roles & Description & References \\
\hline 1 & Policy \& Strategy & $\begin{array}{l}\text { Support and lobby policy makers in the development and implementation of regional, sectorial or } \\
\text { national-wide innovation policy strategies, providing a bridge connection to government and public } \\
\text { entities in matters of innovation. }\end{array}$ & {$[14],[18],[42],[49]$.} \\
\hline 3 & $\begin{array}{l}\text { Knowledge Diffusion } \\
\text { \& Support }\end{array}$ & $\begin{array}{l}\text { Act as two-way communication channel between university and industry, providing a centralized point } \\
\text { of contact to both knowledge diffusion and knowledge support. }\end{array}$ & [4], [8], [14], [16] \\
\hline 5 & $\begin{array}{l}\text { Technology Scouting } \\
\& \text { Market Foresight }\end{array}$ & $\begin{array}{l}\text { Constantly monitor the technology state of the art evolution, scan and gather information to support } \\
\text { innovation decisions and technology procurement. Playing as an input source of market opportunities } \\
\text { through strategic foresight activities, such as identifying and diagnosing market trends, industry' needs } \\
\text { and innovation challenges. }\end{array}$ & $\begin{array}{l}{[5],[8],[27],[30],[46]} \\
{[53],[54]}\end{array}$ \\
\hline 8 & $\begin{array}{l}\text { Project Management \& } \\
\text { Assessment }\end{array}$ & $\begin{array}{l}\text { Assisting with the design, set-up and management of projects properly aligned with defined goals and } \\
\text { needs, interacting regularly with key stakeholders from project administration and execution control } \\
\text { tasks. Also, since acting as neutral third parties, intermediaries can independently assess and evaluate } \\
\text { technology transfer projects performance and its impacts. }\end{array}$ & $\begin{array}{l}{[5],[8],[14],[16],[27],} \\
{[58]}\end{array}$ \\
\hline 9 & $\begin{array}{l}\text { Financial and } \\
\text { Technical Feasibility }\end{array}$ & $\begin{array}{l}\text { Assisting with concept proofing, supplying qualified feasibility analysis and testing, diagnosing and } \\
\text { evaluating ideas, models and technologies' prototypes in order to validate and evaluate its potential. }\end{array}$ & {$[8],[27],[45],[59],[60]$} \\
\hline 10 & $\begin{array}{l}\text { Accreditation \& } \\
\text { Quality }\end{array}$ & $\begin{array}{l}\text { Support in accreditation and standards, aiding in technology regulation and arbitration due diligences } \\
\text { and through quality processes. }\end{array}$ & {$[8],[27],[46]$} \\
\hline 11 & $\begin{array}{l}\text { Intellectual Property \& } \\
\text { Rights }\end{array}$ & $\begin{array}{l}\text { Answer to the } \mathrm{R} \& \mathrm{D} \text { and technology needs through legal strategies, representing and supporting } \\
\text { bureaucratic processes to protect and value intellectual property, rights and other innovation assets. }\end{array}$ & [5], [8], [43], [61] \\
\hline
\end{tabular}

\section{CONCLUSIONS}

The developed framework (Table I), proposed by the authors, intended to systematically synthetize the large contribution pool several authors have been building over the years, allowing to structure and complement some of the ideas found on the literature in a modular and organised way. Thus, despite playing a wide range of roles in innovation and technology transfer, the review results show that most of the intermediation roles are not necessarily related with the key traditional roles of "Brokering" or "Networking" as already suggested by [15].

The main finding standing out from this review is that when it comes to intermediation roles, activities, responsibilities or focus, the literature is largely fragmented and scattered through thousands of publications under different terms and designations, different descriptions and there are few or no connections between the proposed roles.
The developed framework contributes to integrate and structure this heterogeneity and the range of roles played by intermediaries in innovation and technology transfer. Based on the ten roles proposed by [8] the framework incorporates a wide set of authors contributions into new clusters perspectives on the intermediation roles, like "Policy \& Strategy", "Funding \& Finance", "Idealization", "Project Management \& Assessment" and "Marketing and Business Development".

Drawing up on future research directions, the growing relevance that intermediaries show in the innovation systems' literature calls for further theoretical research, frameworks and conceptual models that can lay out how intermediation works, who's involved, what is performed, what are the expected results, and when it should be seen as a critical or a strategic option. 


\section{ACKNOWLEDGEMENT}

This work has been supported by FCT - Fundação para a Ciência e Tecnologia within the R\&D Units Project Scope:UIDB/00319/2020

\section{REFERENCES}

[1] A. Bramwell, N. Hepburn, and D. A. Wolfe, "Growing Innovation Ecosystems: University-Industry Knowledge Transfer and Regional Economic Development in Canada Knowledge Synthesis Paper on Leveraging Investments in HERD Final Report to the Social Sciences and Humanities Research Council of Canada," 2012.

[2] P. Intarakumnerd and P. Chaoroenporn, "The roles of intermediaries and the development of their capabilities in sectoral innovation systems: a case study of Thailand," Asian J. Technol. Innov., vol. 21, no. sup2, pp. 99-114, Nov. 2013.

[3] N. Suvinen, J. Konttinen, and M. Nieminen, "How necessary are intermediary organizations in the commercialization of research?," Eur. Plan. Stud., 2010.

[4] M. Lin and J. Wei, "The impact of innovation intermediary on knowledge transfer," Phys. A Stat. Mech. its Appl., vol. 502, pp. 2128, Jul. 2018

[5] W. Janssen, H. Bouwman, R. van Buuren, and T. Haaker, "An organizational competence model for innovation intermediaries," Eur. J. Innov. Manag., vol. 17, no. 1, pp. 2-24, Jan. 2014.

[6] O. Gassmann, M. Daiber, and E. Enkel, "The role of intermediaries in cross-industry innovation processes," R\&D Manag., vol. 41, no. 5, pp. 457-469, Nov. 2011.

[7] A. T. Alexander and D. P. Martin, "Intermediaries for open innovation: A competence-based comparison of knowledge transfer offices practices," Technol. Forecast. Soc. Change, vol. 80, no. 1, pp. 38-49, Jan. 2013.

[8] J. Howells, "Intermediation and the role of intermediaries in innovation," Res. Policy, vol. 35, no. 5, pp. 715-728, Jun. 2006.

[9] M. Dalziel and S. Parjanen, "Measuring the Impact of Innovation Intermediaries: A Case Study of Tekes," in Practice-Based Innovation: Insights, Applications and Policy Implications, Berlin, Heidelberg: Springer Berlin Heidelberg, 2012, pp. 117-132.

[10] L. Hakkarainen and S. Hyysalo, "The Evolution of Intermediary Activities: Broadening the Concept of Facilitation in Living Labs," Technol. Innov. Manag. Rev., 2016.

[11] H. Chesbrough, W. Vanhaverbeke, and J. West, Open Innovation: Researching a New Paradigm. Oxford: Oxford University Press, 2006.

[12] H. Chesbrough, "From Open Science to Open Innovation," Sci. Bus. Publ., 2015.

[13] M. Agogué et al., "Explicating the role of innovation intermediaries in the 'unknown': a contingency approach,” J. Strateg. Manag., vol. 10, no. 1, pp. 19-39, Feb. 2017

[14] M. Tamtik, "Innovation policy is a team sport' - insights from nongovernmental intermediaries in Canadian innovation ecosystem," Triple Helix, vol. 5, no. 1, p. 8, Dec. 2018.

[15] M. Agogué, A. Yström, and P. Le Masson, "Rethinking the role of intermediaries as an architect of collective exploration and creation of knowledge in open innovation,” Int. J. Innov. Manag., vol. 17, no. 2, p. 1350007, Apr. 2013.

[16] M. Silva, J. Howells, M. Meyer, M. Silva, J. Howells, and M. Meyer, "Innovation intermediaries and collaboration: Knowledge-based practices and internal value creation," Res. Policy, vol. 47, no. 1, pp. 70-87, Feb. 2018.

[17] C. Battistella, A. F. De Toni, and R. Pillon, "Inter-organisational technology/knowledge transfer: a framework from critical literature review," J. Technol. Transf., vol. 41, 2016.

[18] B. Van Der Meulen and A. Rip, "Mediation in the Dutch science system,” Res. Policy, vol. 27, no. 8, pp. 757-769, Dec. 1998.

[19] J. Sapsed, A. Grantham, and R. DeFillippi, "A bridge over troubled waters: Bridging organisations and entrepreneurial opportunities in emerging sectors," Res. Policy, vol. 36, no. 9, pp. 1314-1334, Nov. 2007.

[20] J. Li-Ying, "What do we need from intermediaries for technology transfer to China? A European firm perspective," Prometheus, vol. 30, no. 2, pp. 199-209, Jun. 2012

[21] K. J. Arrow, "The Rate and Direction of Inventive Activity: Economic and Social Factors," Econ. Welf. Alloc. Resour. Invent., pp. 609-626, 1962, Accessed: Mar. 25, 2019.

[22] S. Martin and J. T. Scott, "The nature of innovation market failure and the design of public support for private innovation," 2000.

[23] R. Klein Woolthuis, M. Lankhuizen, and V. Gilsing, "A system failure framework for innovation policy design," Technovation, vol. 25 , no. 6 , pp. 609-619, Jun. 2005.

[24] K. Diener and F. Piller, "The market for open innovation increasing the efficiency and effectiveness of the innovation process," Open Innov. Accel. Surv., vol. TIM Group, no. c, p. 144, 2010.

[25] A. B. Hargadon, "Firms as knowledge brokers: Lessons in pursuing continuous innovation," Calif. Manage. Rev., no. 3, pp. 209-227, Apr. 1998.

[26] R. Garcia and R. Calantone, "A critical look at technological innovation typology and innovativeness terminology: A literature review,” J. Prod. Innov. Manag., vol. 19, no. 2, pp. 110-132, Mar. 2002.

[27] J. Bessant and H. Rush, "Building bridges for innovation: the role of consultants in technology transfer," Res. Policy, vol. 24, no. 1, pp. 97 114, Jan. 1995.

[28] J. Stewart and S. Hyysalo, "Intermediaries, users and social learning in technological innovation," Int. J. Innov. Manag., vol. 12, no. 3, pp. 295-325, Nov. 2008.

[29] F. Damanpour, "Organizational complexity and innovation: Developing and testing multiple contingency models," Manage. Sci., vol. 42, no. 5, pp. 693-716, 1996.

[30] M. Hossain, "Performance and Potential of Open Innovation Intermediaries," Procedia - Soc. Behav. Sci., vol. 58, pp. 754-764, Oct. 2012.

[31] L. Klerkx and C. Leeuwis, "Establishment and embedding of innovation brokers at different innovation system levels: Insights from the Dutch agricultural sector," Technol. Forecast. Soc. Change, vol. 76, no. 6, pp. 849-860, Jul. 2009.

[32] A. Hargadon and R. I. Sutton, "Technology Brokering and Innovation in a Product Development Firm," Adm. Sci. Q., vol. 42, no. 4, p. 716, Dec. 1997.

[33] U. Lichtenthaler and H. Ernst, "External technology commercialization in large firms: Results of a quantitative benchmarking study," R D Manag., vol. 37, no. 5, pp. 383-397, Nov. 2007.

[34] J. Roth, "Enabling knowledge creation: Learning from an R\&D organization,” J. Knowl. Manag., vol. 7, no. 1, pp. 32-48, Mar. 2003.

[35] C. F. Durach, J. Kembro, and A. Wieland, "A New Paradigm for Systematic Literature Reviews in Supply Chain Management," J. Supply Chain Manag., vol. 53, no. 4, pp. 67-85, 2017.

[36] U. Lichtenthaler and H. Ernst, "Intermediary services in the markets for technology: Organizational antecedents and performance consequences," Organ. Stud., vol. 29, no. 7, pp. 1003-1035, Jul. 2008.

[37] Jonhn D.Wolpert, "Breaking Out of the Innovation Box," Harvard Business Review, 2002.

[38] L. H. Lynn, N. M. Reddy, and J. D. Aram, "Linking technology and institutions: The innovation community framework," Res. Policy, vol. 25, no. 1, pp. 91-106, Jan. 1996.

[39] E. Todeva, "Governance of Innovation and Intermediation in Triple Helix Interactions," Ind. High. Educ., vol. 27, no. 4, pp. 263-278, Aug. 2013.

[40] J. H. Sieg, M. W. Wallin, and G. Von Krogh, "Managerial challenges in open innovation: a study of innovation intermediation in the chemical industry," vol. 40, no. 3, Feb., Accessed: Apr. 27, 2020.

[41] J. Surowiecki, "The Wisdom of Crowds: Why the Many are Smarter Than the Few and How ...," How Collect. Wisdom Shapes Bus. Econ. Soc. Nations New York Doubleday, vol. 27, no. 5, p. 296, 2004. 
[42] W. Kanda, O. Hjelm, J. Clausen, and D. Bienkowska, "Roles of intermediaries in supporting eco-innovation," J. Clean. Prod., vol. 205, pp. 1006-1016, Dec. 2018, Accessed: Feb. 04, 2019.

[43] P. Kivimaa, "Government-affiliated intermediary organisations as actors in system-level transitions," Res. Policy, vol. 43, no. 8, pp. 1370-1380, Oct. 2014.

[44] F. Geels and J. J. Deuten, "Local and global dynamics in technological development: a socio-cognitive perspective on knowledge flows and lessons from reinforced concrete," Sci. Public Policy, vol. 33, no. 4, pp. 265-275, May 2006.

[45] K. Matschoss and E. Heiskanen, "Making it experimental in several ways: The work of intermediaries in raising the ambition level in local climate initiatives," J. Clean. Prod., vol. 169, pp. 85-93, Dec. 2017.

[46] M. Pinto, C. Brito, R. Dias, and C. Brito, "Innovation in services: exploring the role of innovation intermediaries," Rev. Port. Mark., vol. 38, no. 34, pp. 53-64, 2015.

[47] F. Polzin, P. von Flotow, and L. Klerkx, "Addressing barriers to ecoinnovation: Exploring the finance mobilisation functions of institutional innovation intermediaries," Technol. Forecast. Soc. Change, vol. 103, pp. 34-46, Feb. 2016.

[48] H. van Lente, M. Hekkert, R. Smits, and B. van Waveren, "Roles of Systemic Intermediaries in Transition Processes," Int. J. Innov. Manag., vol. 07, no. 03, pp. 247-279, Sep. 2003.

[49] R. Smits and S. Kuhlmann, "The rise of systemic instruments in innovation policy," 2004.

[50] A. Bergek et al., "Analyzing the functional dynamics of technological innovation systems: A scheme of analysis," Res. Policy, vol. 37, no. 3, pp. 407-429, 2008, Accessed: Aug. 12, 2020.

[51] P. Clayton, M. Feldman, and N. Lowe, "Behind the scenes Intermediary organizations that facilitate science commercialization through entrepreneurship," 2018.

[52] M. Dias, R. Pinto, I. Saur-Amaral, and C. Melo De Brito, "Innovation intermediaries in service industry: the role of consultancies," J. Innov. Manag. Pinto, Saur-Amaral, Brito JIM, vol. 5, pp. 74-102, 2017.

[53] Y. Back, K. Praveen Parboteeah, and D. Nam, "Innovation in Emerging Markets: The Role of Management Consulting Firms," J. Int. Manag. vol. 20, no. 4, pp. 390-405, Dec. 2014.
[54] B. Becker and O. Gassmann, "Gaining leverage effects from knowledge modes within corporate incubators," R D Manag., vol. 36, no. 1, pp. 1-16, Jan. 2006.

[55] E. Muller and A. Zenker, "Business services as actors of knowledge transformation: the role of KIBS in regional and national innovation systems," Res. Policy, vol. 30, no. 9, pp. 1501-1516, Dec. 2001.

[56] M. Cesário, S. Fernandes, B. Jesus, and J. Monteiro Barata, "Sources of Innovation: The Case of Portuguese Consultancy Sector," J. Technol. Manag. Innov., vol. 10, no. 3, pp. 44-52, Oct. 2015.

[57] D. Pollard, "Innovation and Technology Transfer Intermediaries: A Systemic International Study," in Innovation through Collaboration, 2015, pp. 137-174.

[58] A. Hidalgo and J. Albors, "Innovation management techniques and tools: A review from theory and practice," R D Manag., vol. 38, no. 2, pp. 113-127, Mar. 2008.

[59] R. A. Bendis, R. S. Seline, and E. J. Byler, "A New Direction for Technology-Based Economic Development," Ind. High. Educ., vol. 22 no. 2, pp. 73-80, Apr. 2008.

[60] G. M. Winch and R. Courtney, "The Organization of Innovation Brokers: An International Review," Technol. Anal. Strateg. Manag., vol. 19, no. 6, pp. 747-763, Nov. 2007.

[61] C. Li, T. Lan, and S.-J. Liu, "Patent attorney as technology intermediary: A patent attorney-facilitated model of technology transfer in developing countries," World Pat. Inf., vol. 43, pp. 62-73, Dec. 2015.

[62] L. Klerkx and C. Leeuwis, "Matching demand and supply in the agricultural knowledge infrastructure: Experiences with innovation intermediaries," Food Policy, vol. 33, no. 3, pp. 260-276, Jun. 2008.

[63] J. Albors, E. Sweeney, and A. Hidalgo, "Transnational technology transfer networks for SMEs. A review of the state-of-the art and an analysis of the European IRC network," Prod. Plan. Control, vol. 16, no. 4, pp. 413-423, Jun. 2005.

[64] C. Cantù, J. Ylimäki, C. A. Sirén, and D. Nickell, "The role of knowledge intermediaries in co-managed innovations," J. Bus. Ind. Mark., vol. 30, no. 8, pp. 951-961, Oct. 2015. 